\title{
Effect of Curing and Mixing Methods on the Compressive Strength of Mortar Containing Oil
}

\author{
M H. Almabrok ${ }^{1}$, R G. McLaughlan ${ }^{2}$ and K. Vessalas ${ }^{3}$ \\ Corresponding address ${ }^{2}$ : \\ School of Civil and Environmental Engineering \\ University of Technology, Sydney, Australia \\ Phone: +61 29514 2614. Room: CB11.11.219 \\ Date Received: $2^{\text {nd }}$ March 2015 \\ Date Published: $30^{\text {th }}$ April 2015
}

\begin{abstract}
Oil contaminated fine aggregate is a major environmental concern and can arise as a by product of industrial activities (e.g. oil well drilling and land contamination). Cement-based stabilisation/solidification of oil contaminated materials is an emerging technology however there are some issues that have not been fully addressed. This paper reports the results of a study conducted to investigate the effect of different curing and mixing methods on cement solidification and its consequent effect on the compressive strength of the resultant cementitious product. This work has been done to address leaching concerns during the curing period. The normal curing method for samples to be tested for compressive strength is lime saturated water. However, this method invalidates any subsequent leaching tests. Accordingly, bag curing (BC) and lime saturated water curing (LSW) have been applied using mortar mixed with mineral oil up to $10 \%$ by sand mass under water wet (WW) or oil wet (OW) mixing methods. The results indicate that development in 28 day compressive strength can be achieved without applying water by external means if the moisture movement from the mortar samples is prohibited, irrespective of the mixing methods used.
\end{abstract}

Keywords: Mortar, curing, compressive strength, mixing method, mineral oil

\section{INTRODUCTION}

$\mathrm{O}$ $\mathrm{NE}$ of the most important aspects regarding the performance of monolithic solidified/ stabilised (S/S) material is its ability to resist mechanical stress in the form of a compressive strength test. Compressive strength is linked to the progress of the hydration reaction and the durability of a monolithic S/S material, and is therefore a key variable [1]. The development of the compressive strength of the resultant cementitious product (e.g. mortar) is largely depends on the curing conditions (temperature and humidity) during the curing period [2].

Curing is the process of controlling the rate and extent of moisture loss from mortar during cement hydration. Generally the hydration of cement takes place only if there is enough moisture. This happens at sufficient relative humidity $(\geq 80 \%)$ whereas if the humidity within the capillaries drops below $80 \%$, the hydration almost ceases [3], [4]. Keeping mortar in a moist environment is important in relation to the development of hydration products as it reduces the porosity in hydrated cement and increases the density of the microstructure in mortar [2], [4]. To prevent the moisture movement or evaporation, a proper curing method is needed. This can be accomplished by keeping the mortar elements as saturated as possible in order to produce a strong and durable specimen [5], [6].

Several researchers have discussed the effect of curing condition on the properties of the cementitious product [7]-[9]. However, the effect of the non-standard curing method on the mortar containing oil has not been studied to date. The objective of this paper is to primarily investigate the effect of different curing and mixing methods on the performance (i.e. compressive strength) of mortar containing mineral oil. The fresh properties (flow, wet density and air content) have been tested to identify if they have any effect on the resulting strength.

${ }^{1} \mathrm{PhD}$ Student, School of Civil and Environmental Engineering, Faculty of Engineering, University of Technology, Sydney, Australia, Email: MagdiHussen.Almabrok@student.uts.edu.au

${ }^{2}$ Lecturer, School of Civil and Environmental Engineering, Faculty of Engineering, University of Technology, Sydney, Australia, Email: Robert.McLaughlan@uts.edu.au

${ }^{3}$ Lecturer, School of Civil and Environmental Engineering, Faculty of Engineering, University of Technology, Sydney, Australia, Email: Kirk.Vessalas@uts.edu.au 


\section{METHODOLOGY}

\subsection{Materials}

General Purpose Cement (Cement Australia) which meets the general purpose (GP) requirements specified in AS 3972 [10] was used. The chemical properties of the cement used are shown in Table 1. The fine aggregate was that of Calga double washed sand (Rocla Quarry Products Pty Ltd) with an absorption capacity of $0.65 \%$, specific gravity of 2.57 and median particle size of $0.5 \mathrm{~mm}$. The particle size distribution of Calga sand by sieving method (AS 1411.11.1) [11] is illustrated in Figure 1. The water sourced was of drinking water standard ( $\mathrm{pH} 7.4 ; 2.29 \mu \mathrm{S} / \mathrm{cm}$ ). Glenium, a polycarboxylate ether polymer based high-range water reducing admixture (HWR) (BASF Construction Chemicals Pty Ltd) was used. The mineral oil (Castrol Motorcycle Fork Oil - SAE 10) employed had a viscosity similar to medium crude oil $(\sim 35 \mathrm{~mm} / \mathrm{sec} @$ $40{ }^{\circ} \mathrm{C}$ ).

Table 1 Chemical properties of cement

\begin{tabular}{|l|c|}
\hline \multicolumn{1}{|c|}{ Chemical entity } & Proportion \\
\hline Portland cement clinker & $<97 \%$ \\
\hline Gypsum $(\mathrm{CaSO} 4 \cdot 2 \mathrm{H} 2 \mathrm{O})$ & $2-5 \%$ \\
\hline Limestone $\left(\mathrm{CaCO}_{3}\right)$ & $0-7.5 \%$ \\
\hline Calcium Oxide & $0-3 \%$ \\
\hline Hexavalent Chrome $(\mathrm{Cr} \mathrm{VI})$ & $<20 \mathrm{ppm}$ \\
\hline Crystalline Silica (Quartz) & $<0.04-0.5 \%$ \\
\hline Specific gravity & $3-3.2$ \\
\hline
\end{tabular}

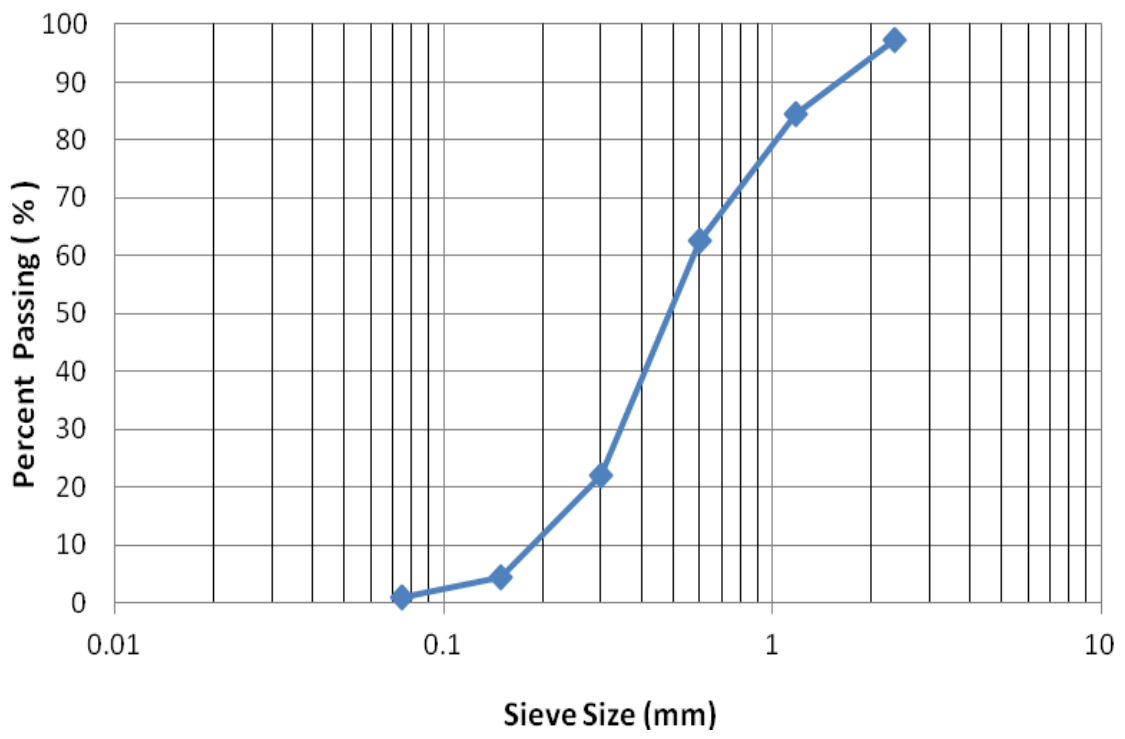

Figure 1 Particle size distribution (sieving method) of Calga double washed sand 


\subsection{Mix proportions}

The composition of the mortar was in accordance with AS 2350.12 [12] with the mix proportions being 1 part of cement and 3 parts of sand (by mass) at a fixed water/cement ratio (w/c) of 0.50 . Each mortar batch comprised cement (225g), fine aggregate $(675 \mathrm{~g})$, water $(112.4 \mathrm{~g})$, and HWR $(0.2 \mathrm{ml})$ with between 0 to $10 \%$ of added oil (by sand mass). This has been reported as 0 to 67.5 grams.

\subsection{Mixing and casting of test samples}

The mixing process followed the procedure outlined in AS 2350.12 [12] except for the oil addition using the Hobart mixer (model N-50 G) mixer. Two different mixing protocols (water-wet; oil-wet) were used. For the water wet method, mineral oil was weighed ( $\%$ by sand mass) and premixed thoroughly with sand for $5-7$ minutes using a spatula before adding to the other ingredients. For the oil wet method, the same mixing procedure as specified for the water wet method was followed unless the oil was mixed with cement instead of sand. All laboratory work was conducted at $22 \pm 2 \mathrm{C}^{\circ}$. HWR was added directly to water before the commencement of mixing and it was used with all the mixes to give reproducible flow $(60 \pm 10 \%)$. This proved to be most suitable for proper consolidation of the samples by hand. The protocol for moulding the mortar (ASTM C109) [13] was adopted and modified to minimise any impact of the protocol on any subsequent leaching tests. No mould-release agent was used; instead, cube moulds were lined with non-sticking tape. The moulds containing consolidated mortar were sealed in zip lock plastic bags to prevent moisture loss and stored in a moist atmosphere for 24 hours. Demoulding took place thereafter and triplicate mortar specimens having 50 x 50 x $50 \mathrm{~mm}$ dimensions were then again sealed in zip lock plastic bags and placed into a curing tank filled with water for up to 28 days at a temperature of $22 \pm 0.5^{\circ} \mathrm{C}$. Testing for fresh properties was also done on triplicate samples.

\subsection{Curing methods}

Once the samples were stripped from their respective mould, demoulding took place and the samples were cured under two types of curing until the day of testing. These were bag curing (BC) and lime saturated water curing (LSW). In bag curing, the samples were sealed in zip lock plastic bags and thereafter placed in plastic container with lid filled with water. In lime saturated water, lime $(3 \mathrm{~g} / \mathrm{L})$ was used to saturate the curing water. The curing temperature was maintained at $22 \pm 2{ }^{\circ} \mathrm{C}$ in all of the curing methods.

\subsection{Testing procedures}

Flow was determined by the spread diameter on a hand driven flow table. Wet density was assessed based on the mass per unit volume of freshly mixed mortar. The air content was measured by the means of the air entrainment meter (TESTING Bluhm \& Feuerherdt $\mathrm{GmbH}$ ). The compressive strength was determined using an Avery Compression Testing Machine (ACTM) with a maximum capacity of $1993 \mathrm{kN}$ following the listed procedures of the test method ASTM C109 [13]. Vertical load at a rate of $1.5 \mathrm{kN} / \mathrm{sec}$ was exerted on the samples and the maximum load indicated by the testing machine (load at failure) was recorded.

\section{EXPERIMENTAL RESULTS AND DISCUSSION}

\subsection{Fresh properties}

The flow of all mortar mixes were $60 \pm 10 \%$ with $0.2 \mathrm{ml} \mathrm{HWR}$ whether the water wet or oil wet are used as the mixing method indicating that the mixing method has no significant effect on flow (Table 2).

Wet densities were found to decrease with increasing oil addition levels irrespective of the type of mixing method (Table 2 ). The reduction in the wet density ranged from approximately $2 \%$ to $9 \%$ for both methods compared to the control mix. This reduction can be attributed to the oil free mortar $\left(2270 \mathrm{~kg} / \mathrm{m}^{3}\right)$ being replaced by lower density oils $\left(866 \mathrm{~kg} / \mathrm{m}^{3}\right)$ when it is placed in a mould of a fixed volume rather than being the result of any effects of the mixing method.

As a general trend, the percentage of air content decreases with increased oil content in the mortar mixes (Table 2). However, it is noted that the air content is not of a significant effect due to the use of different mixing methods (water wet and oil wet) where the air content in the both methods varies from $3-7 \%$. 
Table 2 Fresh properties of mortar for water wet and oil wet mixing methods

\begin{tabular}{|c|c|c|c|c|c|c|c|c|}
\hline \multicolumn{2}{|c|}{ Oil content } & \multirow{2}{*}{$\begin{array}{c}\text { Mix } \\
(\%)\end{array}$} & \multicolumn{2}{|c|}{ Flow } & \multicolumn{2}{c|}{ Wet density } & \multicolumn{2}{c|}{ Air content } \\
\cline { 5 - 8 } & method & $(\%)$ & STDEV & $\left(\mathrm{kg} / \mathrm{m}^{3}\right)$ & STDEV & $(\%)$ & STDEV \\
\hline 0 & 0 & WW & 54 & 1.0 & 2270 & 1.2 & 6.4 & 0.5 \\
\hline 2 & 13.5 & WW & 70 & 1.0 & 2222 & 1.0 & 7.0 & 0.2 \\
\hline 4 & 27.0 & WW & 63 & 2.1 & 2176 & 1.5 & 6.3 & 0.3 \\
\hline 6 & 40.5 & WW & 62 & 1.7 & 2136 & 0.6 & 5.7 & 0.4 \\
\hline 8 & 54.0 & WW & 62 & 1.4 & 2096 & 1.5 & 4.8 & 0.2 \\
\hline 10 & 67.5 & WW & 70 & 1.3 & 2060 & 1.2 & 3.2 & 0.3 \\
\hline 2 & 13.5 & OW & 69 & 1.7 & 2224 & 1.2 & 6.5 & 0.5 \\
\hline 4 & 27.0 & OW & 64 & 1.3 & 2180 & 1.0 & 5.9 & 0.6 \\
\hline 6 & 40.5 & OW & 62 & 1.7 & 2139 & 0.6 & 5.5 & 0.4 \\
\hline 8 & 54.0 & OW & 61 & 1.3 & 2100 & 1.2 & 4.3 & 0.2 \\
\hline 10 & 67.5 & OW & 65 & 1.0 & 2062 & 1.0 & 3.2 & 0.2 \\
\hline
\end{tabular}

WW: water wet OW: oil wet

STDEV: standard deviation

\subsection{Compressive strength}

The behaviour of 7 and 28 days compressive strength of all samples incorporating oil was quite different from that without oil (Figure 2, Figure 3). All mixes follow a similar trend where higher oil contents in mortars resulted in decreased compressive strength. An increase in the compressive strength with age ( 7 versus 28 days) was noted in all the mortar samples, irrespective of the curing or mixing methods utilised. However, for the water wet oil containing samples, the compressive strength development is greater at 7 and 28 days in the lime cured samples than for the bags cured ones. The difference is not significant based on the scatter which was evident in the error bars (Figure 2). The 7 day compressive strength for the BC oil wet samples has greater early stage development compared to the equivalent 7 day LSW cured samples. However at later times ( 28 days) there is no significant difference based on the samples variability measured by error bars (Figure 3). Further work is needed to better understand these early stage hydration processes in oil contaminated mortars.

The overall finding of this investigation indicated that the curing methods do not have a significant effect on the development of 28 day compressive strength. This is attributed to there being sufficient moisture and suitable vapour pressure present in both methods which together work to maintain the hydration of the cement. The results of the bagged cured generally indicate that the development in compressive strength can be achieved without applying water by external means if the moisture movement from the mortar samples is prohibited.

Reference [14] also tested different curing methods and indicate that regardless of the curing method used, the compressive strength of concrete increases with increasing age and there is no significant difference between the methods employed. Indeed, they found that the compressive strength of water cured microsilica concrete was 56.60 and $64.81 \mathrm{MPa}$ at 28 and 91 days, respectively. Wrapped curing (equivalent to $\mathrm{BC}$ ) produced a compressive strength close to that of water curing. Wrapped curing provided a compressive strength of 55.50 and $62 \mathrm{MPa}$ at 28 and 91 days, respectively. 


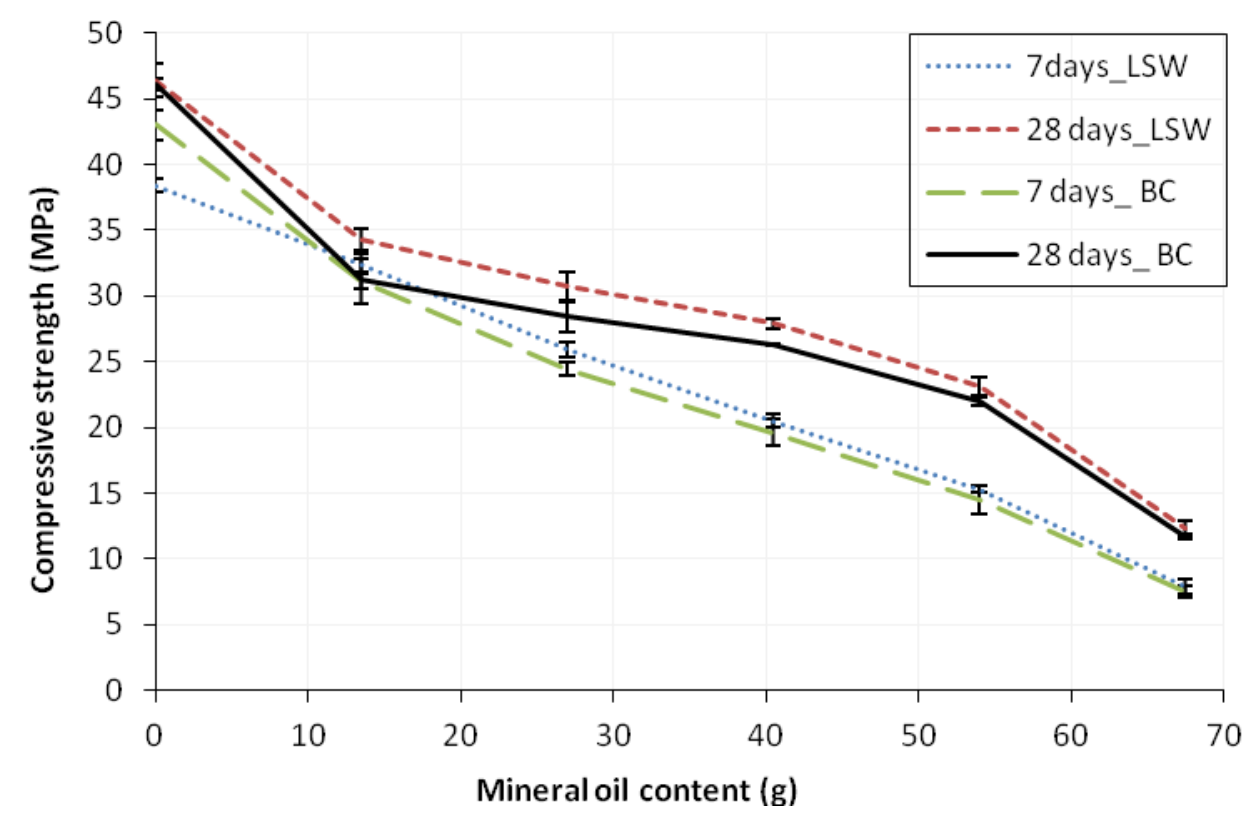

Figure 2 Variation in compressive strength for mortar mixes containing mineral oil using the water wet (WW) method for bag curing (BC) and lime saturated water curing (LSW)

(Error bars equal average \pm standard deviation)

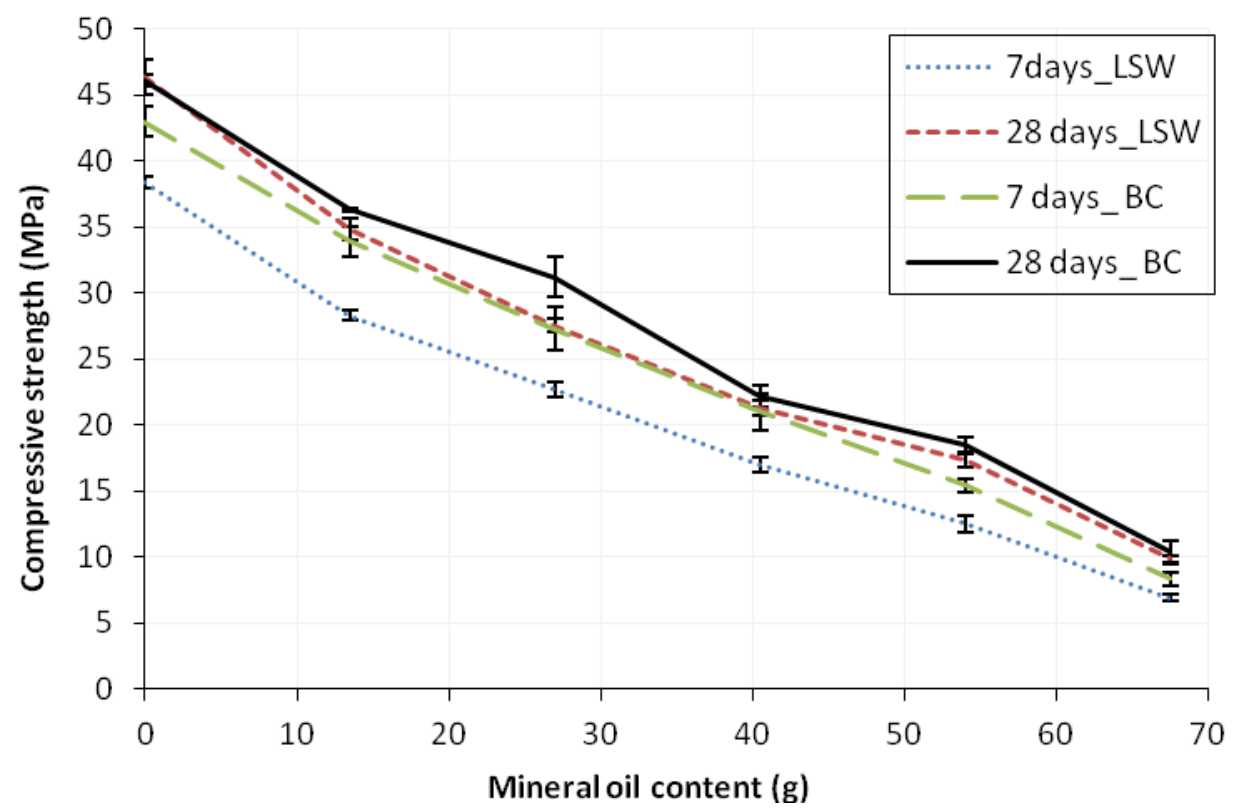

Figure 3 Variation in compressive strength for mortar mixes containing mineral oil using the oil wet $(\mathrm{OW})$ method for bag curing $(\mathrm{BC})$ and lime saturated water curing (LSW)

(Error bars equal average \pm standard deviation) 


\section{CONCLUSION}

Cement - based stabilisation/solidification of oil contaminated material is an emerging technology however there is limited knowledge on the effects of the curing and mixing methods in relation to the properties of the resultant cementitious mix. With regard to the inhibition of cement hydration and its consequent effects on compressive strength, the overall finding of this investigation indicates that the fraction of oil in the mortar plays a more important role than the curing or mixing methods.

Despite the fact that in the oil wet method, the oil is coated the cement particles prior to contacting the water, the water wet and oil wet methods exhibit the same trend, whereby higher oil content in mortar results in decreased compressive strength with strength developing from 7 to 28 days. Furthermore, it was found that a bag-cured protocol developed for this research was able to produce mortars with almost similar physical properties to that produced by the standard lime saturated curing protocol. The development of compressive strength with maturity shows that cement hydration occurs in all mixes but to varying degrees. This may be attributed to there being sufficient moisture and suitable vapour pressure present in both methods which in tandem works to maintain the hydration of the cement.

\section{ACKNOWLEDGMENT}

The authors gratefully acknowledge the financial support provided by the Libyan Embassy in Australia for this research. The authors also acknowledge the support and cooperation provided by Mr. Rami Hadad, Manager, Civil Laboratories at the University of Technology, Sydney. Finally, the authors extend their special gratitude to the Rocla Quarries for providing the Calga sand used in this investigative work.

\section{REFERENCES}

[1] A. AL-Tabbaa, A. S. Perera, "Stabilisation/solidification treatment and remediation. Part IV: Testing and performance criteria," In Proceedings of the International Conference on Stabilisation/Solidification Treatment and Remediation, Cambridge, UK, 2005, pp. 415-435.

[2] M. R. Aminur, M. R. Harunur, D. C. L. Teo and M. M. Abu Zakir, "Effect of aggregates and curing conditions on the compressive strength of concrete with age," UNIMAS e-Journal of Civil Engineering, vol. 1, issue. 2, pp. 1- 6, 2010.

[3] A. M. Neville, Properties of Concrete. $4^{\text {th }}$ and Final ed. UK: Pearson Education Limited, 2009.

[4] M. Safiuddin, S. N. Raman, and M. F. M. Zain, "Effect of different curing methods on the properties of microsilica concrete, ”Australian Journal of Basic and Applied Sciences, vol. 1, issue. 2, pp. 87-95, 2007.

[5] N. Gowripalan, J. G. Cabrera, A. R, Cusens and P. J. Wainwright, "Effect of curing on durability, "in Durable Concrete (ACI Compilation 24), American Concrete Institute, Michigan: Farmington Hills, January 1992, pp. 47-54.

[6] M. F. M. Zain and Y. Matsufuji,"The influence of curing methods on the physical properties of high strength concrete exposed to medium temperature $\left(20-50{ }^{\circ} \mathrm{C}\right)$, "In the proceeding of the 5th international Conference on Concrete Engineering and Technology, Kuala Lumpur, Malaysia, 1997.

[7] A. S. Al-Gahtani, "Effect of curing methods on the properties of plain and blended cement concretes, "Construction and Building Materials, vol. 24, pp. 308-314, 2010.

[8] M. N. Qureshi and S. Ghosh, "Effect of curing conditions on the compressive strength and microstructure of alkaliactivated GGBS paste, ” International Journal of Engineering Science Invention, vol. 2, issue. 2, pp. 24 -31, 2013.

[9] K. Tan and O. E. Gjorv, "Performance of concrete under different curing conditions, " Cement and Concrere Research, vol. 26, issue. 3, pp. 355-361, 1996.

[10] AS 3922, "Portland and blended cements," Standards Australia International Ltd, 2010.

[11] AS 1141,"Method for sampling and testing aggregates. Method 11.1: Particle size distribution - sieving method," Standards Australia International Ltd, 2009.

[12] AS 2350.12, "Methods of testing portland, blended and masonry cements. Method 12 : Preparation of a standard mortar and moulding of specimens," Standards Australia International Ltd, 2006.

[13] ASTM C109/C109M, "Standard test method for compressive strength of hydraulic cement mortars (using 50 mm cube specimens), ”ASTM International, 2008

[14] M. Safiuddin, S. N. Raman and M. F.M. Zain, "Effect of different curing methods on the properties of microsilica concrete, ” Australian Journal of Basic and Applied Sciences, vol. 2, issue. 1, pp. 87-95, 2007. 